\title{
Prevalence of Idiopathic Peptic Ulcer in Southeastern Iran
}

\author{
Alireza Bakhshipour (10) ${ }^{1}$ and Raheleh Rafaiee (iD) ${ }^{2, *}$ \\ ${ }^{1}$ Infectious Diseases and Tropical Medicine Research Center, Resistant Tuberculosis Institute, Zahedan University of Medical Sciences, Zahedan, Iran \\ ${ }^{2}$ Department of Neuroscience, School of Advanced Technologies in Medicine, Mazandaran University of Medical Sciences, Sari, Iran \\ "Corresponding author: Department of Neuroscience, School of Advanced Technologies in Medicine, Mazandaran University of Medical Sciences, Sari, Iran. Email: \\ rachel.rafaie@yahoo.com
}

Received 2021 September 15; Accepted 2021 September 29.

\begin{abstract}
Background: The idiopathic peptic ulcers (IPU) or non-Helicobacter pylori, non-steroidal anti-inflammatory drug non-NSAIDs associated peptic ulcers are a serious therapeutic challenge. The prevalence of IPU is increasing in some parts of the world.

Objectives: This study aimed to determine the prevalence of IPU in southeastern Iran.

Methods: In this cross-sectional study, a total of 367 patients with active peptic ulcer were diagnosed by endoscopy between Jan 2018 and Feb 2019. The patients were assessed for history of medication use (including NSAIDs) in the past month, smoking, alcohol, as well as a complete history of health problems related to underlying disease such as cardiopulmonary, hepatic, renal problems, and chronic pancreatitis. Biopsy samples from antrum were performed for rapid urease test (RUT), and if RUT was negative, then biopsies were sent for histopathology. If both RUT and pathologic findings were negative for $H$. pylori, in patients who had treatment for $H$. pylori eradication, anti-H. pylori IgG antibody of blood samples was assessed. Patients were considered infected with $H$. pylori if any of the diagnostic tests had a positive result.

Results: According to the results, 336 (91.3\%) cases had at least one of the two main etiologic factors (H. pylori and NSAIDs) for peptic ulcer. While 323 (87.7\%) patients were H. pylori-positive, 45 (12.3\%) patients were H. pylori-negative. However, out of 45 H. pylori-negative cases, 13 patients had a positive history of using NSAIDs, and 32 (8.69\%) patients were IPU.

Conclusions: Our study showed that both H. pylori infection and NSAIDs use remain the main cause of peptic ulcers, and the prevalence of IPU is relatively high in Zahedan.
\end{abstract}

Keywords: Helicobacter pylori, Idiopathic, Non-Steroidal Anti-Inflammatory Drugs, NSAIDs, Ulcer, Iran

\section{Background}

Infection of Helicobacter pylori and the use of nonsteroidal anti-inflammatory drugs (NSAIDs) are the two main causes of peptic ulcer disease $(1,2)$. By the end of the 20th century, almost all peptic ulcers were considered idiopathic. Marshall BJ and Warren JR. showed the association between the infection of $H$. pylori with gastritis and peptic ulceration. This was one of the most important events in the history of peptic ulcers and significantly altered the natural course and treatment of ulcers (3). At present, the most appropriate treatment for peptic ulcers due to $H$. $p y$ lori is eradication therapy, which significantly reduces the relapse rate of peptic ulcers (4).

Literature reported $H$. pylori infection is more common in developing countries than in developed countries and is about $100 \%$ in some areas (5). However, more recent studies showed H. pylori infection has decreased in some Asian regions (6). In this regard, multiple factors such as successful $H$. pylori eradication therapy and increased healthy lifestyle may be involved (7). Peptic ulcers that do not relate to H. pylori infection or taking NSAIDs are considered idiopathic peptic ulcers (IPU). The IPU, in comparison with other peptic ulcers with known causes, has a worse prognosis, more relapse rate, more complications such as bleeding, and difficult treatment/recovery (8). Some reports showed an increase in the prevalence of IPU, particularly in developed regions of the world (9).

Although numerous epidemiological studies have shown alternation in the etiological factor for peptic ulcers, few research has been conducted on this issue in Iran. Hence, it seems necessary to define the strategies and future management of peptic ulcer diseases in our region.

\section{Objectives}

This study aimed to determine the prevalence of IPU in southeastern Iran. 


\section{Methods}

This cross-sectional study was conducted at a 1000bed, university-affiliated hospital in Zahedan, Iran. The research ethics committee evaluated and approved the study. Eligible patients were selected by the available sampling method. The subjects were patients with active peptic ulcer endoscopically diagnosed between Jan 2018 and Feb 2019. An ulcer was defined as an active mucosal lesion with observable submucosal depth and longest diameter of $\geq 5 \mathrm{~mm}$. Written informed consent was obtained from all participants, and the research objectives were explained prior to participation. The participants with an age of $<18$ years were included if their parents signed an informed consent. Patients with any malignancy, malignant gastric ulcers, and history of peptic ulcer surgery were excluded.

According to previous studies in Iran, $\mathrm{P}=0.6, \mathrm{Z}_{(1-\alpha) \mid 2}=$ 1.96 , and $d=0.05$, the sample size was calculated as 368 participants. The sample size was measured using the following formula for sample calculation:

Sample Size $=\frac{Z_{\frac{1-\alpha}{2}}^{2} \times P(1-P)}{d^{2}}$

The patients' basic demographics, history of medication use (including NSAIDs) in the past month, smoking, alcohol, as well as a complete history of health problems related to underlying diseases such as cardiopulmonary, hepatic, renal problems, and chronic pancreatitis were taken from the patients upon visiting and were recorded in the baseline forms.

During the upper gastrointestinal endoscopy, biopsies were performed at the antrum of gastric mucosa, and rapid urease test (RUT, sensitivity 85 - 95\%, specificity 95 - 100\%) was done for the tissue samples, and if H. pylorinegative, other samples were sent to the laboratory of pathology to observe $H$. pylori on a biopsy smear after hematoxylin-eosin staining (sensitivity $80-90 \%$, specificity $>95 \%$ ). In patients who did not have a treatment for $H$. pylori eradication, anti-H. pylori IgG antibody (sensitivity > $80 \%$, specificity $>90 \%$ ) of blood samples was requested.

Patients were considered infected with $H$. pylori if any of the diagnostic tests had a positive result. SPSS software version 17 was used for data process and analysis. Descriptive statistics (e.g., frequency and percentage) were calculated. Also, comparisons between $H$. pylori-positive and $H$. pylori-negative patients and categorical variables were made by chi-square test. P-value $<0.05$ was considered as statistically significant.

\section{Results}

In this study, out of a total of 368 included patients with peptic ulcer, 336 (91.3\%) had at least one of the two main etiologic factors (H. pylori and NSAIDs) for peptic ulcer. Also, 323 (87.7\%) patients were $H$. pylori-positive, of whom 309 (84\%) patients had a positive RUT, $3(0.8 \%)$ patients had a positive histological smear, and $4(1.1 \%)$ patients had a positive serology. Moreover, 45 (12.3\%) patients were $H$. pylorinegative, and 32 (8.69\%) patients had IUP. Among patients with IUP, one patient had chronic obstructive pulmonary disease (COPD), two patients had cirrhosis, and three patients had renal stone; other cases had no underlying disease.

Table 1 presents more detailed information about the etiologies of peptic ulcers in our sample. Locations of ulcers and demographic characteristics of the patients are shown in Table 2.

\begin{tabular}{lcc}
\hline Table 1. Etiologies of Peptic Ulcer in Our Sample $(\mathrm{n}=368)$ & \\
\hline Etiology & Number of Patients & \% of Total Sample \\
\hline H.pylori-positive & 323 & 87.7 \\
NSAID use & 95 & 25.81 \\
\hline NSAID + H.pylori-positive & 82 & 22.28 \\
NSAID + H.pylori-negative & 13 & 3.53 \\
\hline Idiopathic peptic ulcer & 32 & 8.69 \\
\hline
\end{tabular}

Abbreviation: DU, duodenal ulcer; GU, gastric ulcer; NSAID, nonsteroidal antiinflammatory drugs.

\section{Discussion}

This study adds to the literature on the prevalence of $H$. pylori-positive and $H$. pylori-negative peptic ulcers and provides an estimation of the prevalence of IPU in southeastern Iran. The etiological role of $H$. pylori and NSAIDs in endoscopically diagnosed gastric and duodenal ulcers showed the involvement of these two main causes in $91.3 \%$ of peptic ulcer cases in this study. We also found no significant association between $H$. pylori infection and the patients' demographics (age and gender), smoking, and use of NSAIDs in our patients.

Our findings are in accordance with the past to present literature, which showed a remarkably higher prevalence of $H$. pylori-related peptic ulcers $(10,11)$; also, duodenal ulcer (DU) was more common than gastric ulcer (GU) (12). Considering the demographic characteristics of the patients with peptic ulcer, they were as young as samples in other similar studies (13), and H.pylori-related peptic ulcers showed a male predominance (14). A systematic review and 
Bakhshipour A and Rafaiee $R$

\begin{tabular}{|c|c|c|c|c|}
\hline \multirow{2}{*}{ Variables } & \multirow{2}{*}{ Total } & \multicolumn{2}{|c|}{ H. pylori Infection } & \multirow{2}{*}{ P-Value } \\
\hline & & Positive & Negative & \\
\hline Ulcer location & & & & 0.88 \\
\hline DU & $309(83.96)$ & $272(88)$ & $37(12)$ & \\
\hline GU & $47(12.77)$ & $41(87.8)$ & $6(12.2)$ & \\
\hline $\mathrm{DU}+\mathrm{GU}$ & $12(17.64)$ & $10(83.3)$ & $2(16.7)$ & \\
\hline Gender & & & & 0.50 \\
\hline Male & $237(64.4)$ & $206(86.9)$ & $31(13.1)$ & \\
\hline Female & $131(35.6)$ & $117(89.3)$ & $14(10.7)$ & \\
\hline Age groups (y) & & & & 0.49 \\
\hline $10-19$ & $13(3.5)$ & $12(7.7)$ & $1(92.3)$ & \\
\hline $20-29$ & $85(23.1)$ & $70(82.4)$ & $15(17.6)$ & \\
\hline $30-39$ & $81(22)$ & $69(85.2)$ & $12(14.8)$ & \\
\hline $40-49$ & $55(15)$ & $51(97.2)$ & $4(7.3)$ & \\
\hline $50-59$ & $51(13.85)$ & $47(92.2)$ & $4(7.8)$ & \\
\hline $60-69$ & $44(11.95)$ & $39(88.6)$ & $5(11.4)$ & \\
\hline$\geq 70$ & $39(10.6)$ & $35(89.7)$ & $4(10.3)$ & \\
\hline Current smoking & & & & 0.49 \\
\hline Yes & $44(11.95)$ & $40(90.9)$ & $4(9.1)$ & \\
\hline No & $324(88.05)$ & $283(87.3)$ & $41(12.7)$ & \\
\hline NSAID use & & & & 0.61 \\
\hline Yes & $95(25.81)$ & $82(86.3)$ & $13(13.7)$ & \\
\hline No & $273(74.19)$ & $241(88.3)$ & $32(11.7)$ & \\
\hline
\end{tabular}

Abbreviation: DU, duodenal ulcer; GU, gastric ulcer; NSAID, nonsteroidal anti-inflammatory drugs.

${ }^{a}$ Value are expressed as No. (\%).

meta-analysis of 80 studies from Iran in 2018 found that the prevalence of peptic ulcers in Iran was 34\%, which was higher than the global rate (6 to $15 \%$ ), and the prevalence of H. pylori-positive ulcers was $62 \%$ in patients with peptic ulcer (15). Also, in contrast with our results, the mentioned review showed that one of the environmental causes of peptic ulcers is smoking (15). This inconsistency might be attributed to the fact that most of the included samples in our study were non-smoker individuals. As several studies reported (16-18), in the present study, the current smokers had more positivity to $H$. pylori than nonsmoker patients with peptic ulcer. The same reason may be applied to the inconsistency of NSAIDs use, and most of our samples were not chronic NSAIDs user.

Our data indicated that the incidence of IPU or nonNSAID, non-H. pylori associated peptic ulcers was $8.69 \%$, which is close to another study (13.11\%) from Iran (19). Seyed Mirzaei et al. (2015) found that the prevalence of IPU in Kerman (southern Iran) was $1.8 \%$, which was lower than the rates found in our province. Regarding their method, polymerase chain reaction (PCR) test was used on tissue samples that increased $H$. pylori detection rate (20). Numerous studies have been published since 1996 with different results showing the prevalence of IUP range from 0.8 to $40 \%$, which seems to be due to the health promotion of the population and the diagnostic accuracy of the used tests (21, 22). A review study reported that IPU comprised $10-30 \%$ of all peptic ulcers in Asia (21). Overall, a review of the literature indicated an increase in the prevalence of IUP. Most of the available evidence suggested that IPUs are more likely resistant to acid suppression therapy and are related to a high risk of recurrence and bleeding and more mortality in comparison with H. pylori-positive peptic ulcer (23).

However, in most studies, the techniques of detecting H. pylori were RUT, respiratory urea test, fecal antigen test, histology, serology, or a combination of mentioned techniques with about 95\% diagnostic sensitivity (2). It should also be noted that some patients had false negative tests 
for $H$. pylori due to the low bacterial load in the tissue, recent usage of antibiotics or proton pump inhibitors medications $(24,25)$.

Various etiological risk factors involved in upper GI ulceration are not yet entirely understood. However, several factors have been found to be important in the pathogenesis of peptic ulcer, including the medications such as spironolactone (26) and selective serotonin reuptake inhibitors (SSRIs) (27), as well as underlying diseases such as cirrhosis $\operatorname{COPD}(28,29)$, renal stones, chronic pancreatitis, coronary artery disease (CAD), and polycythemia vera (30). Given the high prevalence of asymptomatic CAD in our society, a percentage of our patients may be prone to IPU due to CAD (31).

This study had some limitations. First, due to a possible defect in tissue sampling, many false negative results occurred in the URT as well as histological investigation, and if tissue culture had been performed, the chances of positive results for $H$. pylori were much higher. Second, despite our efforts to obtain accurate medical history, patients may not have reported NSAIDs usage, and this may have contributed to the high rate of IPU in our study. On the other hand, unlike previous similar studies, the large sample size in this research may be considered as one of the strengths of the current study. Our results are crucial for clinical practice to diagnose and monitor the trends related to peptic ulcer diseases over time in our population.

\subsection{Conclusion}

Our study showed that both $H$. pylori infection and NSAIDs use remain the main cause of peptic ulcers, and the prevalence of IPU is relatively high in Zahedan.

\section{Acknowledgments}

The authors would like to thank the participants for their contributions. Also, the authors wish to thank the Zahedan University of Medical Sciences.

\section{Footnotes}

Authors' Contribution: A.R.B. designed the study, supervised collecting the data, and wrote the draft of manuscript. R.R. involved in planning and worked on the manuscript. All authors contributed to the final version of the manuscript.

Conflict of Interests: The authors declare that they have no conflict of interest.

Ethical Approval: The present study was completed in accordance with the Declaration of Helsinki and the Ethical
Guidelines for Medical and Health research established by the Iranian Ministry of Health and Medical Education and Ministry of Science, Research, and Technology of Iran. The Ethics Review Committee of Zahedan University of Medical Sciences, Iran, approved the study (registration No. IR.ZAUMS.REC.1390.1278).

Funding/Support: The current research was funded by a specific project grant from Zahedan University of Medical Sciences.

Informed Consent: A written informed consent obtained from the participants or their parents.

\section{References}

1. Drini M. Peptic ulcer disease and non-steroidal anti-inflammatory drugs. Aust Prescr. 2017;40(3):91-3. doi: 10.18773/austprescr.2017.037. [PubMed: 28798512]. [PubMed Central: PMC5478398].

2. Narayanan M, Reddy KM, Marsicano E. Peptic ulcer disease and Helicobacter pylori infection. Mo Med. 2018;115(3):219-24. [PubMed: 30228726]. [PubMed Central: PMC6140150].

3. Charitos IA, D'Agostino D, Topi S, Bottalico L. 40 years of Helicobacter pylori: A revolution in biomedical thought. Gastroenterol Insights. 2021;12(2):111-35. doi: 10.3390/gastroent12020011.

4. Ford AC, Gurusamy KS, Delaney B, Forman D, Moayyedi P. Eradication therapy for peptic ulcer disease in Helicobacter pyloripositive people. Cochrane Database Syst Rev. 2016;4. CD003840. doi: 10.1002/14651858.CD003840.pub5. [PubMed: 27092708]. [PubMed Central: PMC7163278].

5. Salih BA. Helicobacter pylori infection in developing countries: The burden for how long? Saudi J Gastroenterol. 2009;15(3):201-7. doi: 10.4103/1319-3767.54743. [PubMed: 19636185].

6. Nagy P, Johansson S, Molloy-Bland M. Systematic review of time trends in the prevalence of Helicobacter pylori infection in China and the USA. Gut Pathog. 2016;8:8. doi: 10.1186/s13099-016-0091-7. [PubMed: 26981156]. [PubMed Central: PMC4791971].

7. $\mathrm{Hu} \mathrm{Y}$, Zhu Y, Lu NH. Recent progress in Helicobacter pylori treatment. Chin Med J (Engl). 2020;133(3):335-43. doi: 10.1097/CM9.0000000000000618. [PubMed: 31929363]. [PubMed Central: PMC7004604].

8. Sverden E, Agreus L, Dunn JM, Lagergren J. Peptic ulcer disease. BMJ. 2019;367:15495. doi: 10.1136/bmj.l5495. [PubMed: 31578179].

9. Nakamura M, Overby A, Michimae H, Matsui H, Takahashi S, Mabe K, et al. PCR analysis and specific immunohistochemistry revealing a high prevalence of non-Helicobacter pylori Helicobacters in Helicobacter pylori-negative gastric disease patients in Japan: High susceptibility to an Hp eradication regimen. Helicobacter. 2020;25(5). e12700. doi: 10.1111/hel.12700. [PubMed: 32790220].

10. Hooi JKY, Lai WY, Ng WK, Suen MMY, Underwood FE, Tanyingoh D, et al. Global prevalence of Helicobacter pylori infection: Systematic review and meta-analysis. Gastroenterology. 2017;153(2):420-9. doi: 10.1053/j.gastro.2017.04.022. [PubMed: 28456631].

11. Taylor DN, Blaser MJ. The epidemiology of Helicobacter pylori infection. Epidemiol Rev. 1991;13:42-59. doi: 10.1093/oxfordjournals.epirev.a036078. [PubMed: 1765119].

12. Graham DY. History of Helicobacter pylori, duodenal ulcer, gastric ulcer and gastric cancer. World J Gastroenterol. 2014;20(18):5191-204. doi: 10.3748/wjg.v20.i18.5191. [PubMed: 24833849]. [PubMed Central: PMC4017034]. 
13. Magalhaes Queiroz DM, Luzza F. Epidemiology of Helicobacter pylori infection. Helicobacter. 2006;11(Suppl 1):1-5. doi: 10.1111/j.1478405X.2006.00429.x. [PubMed: 16925604].

14. Moshkowitz M, Horowitz N, Beit-Or A, Halpern Z, Santo E. Genderassociated differences in urea breath test for Helicobacter pylori infection referrals and results among dyspeptic patients. World J Gastrointest Pathophysiol. 2012;3(3):80-4. doi: 10.4291/wjgp.v3.i3.80. [PubMed: 22737592]. [PubMed Central: PMC3382706].

15. Sayehmiri K, Abangah G, Kalvandi G, Tavan H, Aazami S. Prevalence of peptic ulcer in Iran: Systematic review and meta-analysis methods.JRes Med Sci. 2018;23:8. doi:10.4103/jrms.JRMS_1035_16.[PubMed: 29456565]. [PubMed Central: PMC5813297].

16. Li LF, Chan RL, Lu L, Shen J, Zhang L, Wu WK, et al. Cigarette smoking and gastrointestinal diseases: The causal relationship and underlying molecular mechanisms. Int JMol Med. 2014;34(2):372-80. doi: 10.3892/ijmm.2014.1786. [PubMed: 24859303].

17. Bateson MC. Cigarette smoking and Helicobacter pylori infection. Postgrad Med J. 1993;69(807):41-4. doi: 10.1136/pgmj.69.807.41. [PubMed: 8446549]. [PubMed Central: PMC2399577].

18. Camargo MC, Piazuelo MB, Mera RM, Fontham ET, Delgado AG, Yepez $\mathrm{MC}$, et al. Effect of smoking on failure of $\mathrm{H}$. pylori therapy and gastric histology in a high gastric cancer risk area of Colombia.Acta Gastroenterol Latinoam. 2007;37(4):238-45. [PubMed:18254262].

19. Rajabalinia H, Ghobakhlou M, Nikpour S, Dabiri R, Bahriny R, Sherafat SJ, et al. Non-Helicobacter pylori, non-NSAIDs peptic ulcers: A descriptive study on patients referred to Taleghani hospital with upper gastrointestinal bleeding. Gastroenterol Hepatol Bed Bench. 2012;5(4):1906. [PubMed: 24834225]. [PubMed Central: PMC4017462].

20. Seyed Mirzaei SM, Zahedi MJ, Shafiei Pour S. Prevalence of Helicobacter pylori-negative, non-steroidal anti-inflammatory drug related peptic ulcer disease in patients referred to Afzalipour hospital. Middle East J Dig Dis. 2015;7(4):241-4. [PubMed: 26609353]. [PubMed Central: PMC4655845].

21. Iijima K, Kanno T, Koike T, Shimosegawa T. Helicobacter pylorinegative, non-steroidal anti-inflammatory drug: Negative idiopathic ulcers in Asia. World J Gastroenterol. 2014;20(3):706-13. doi: 10.3748/wjg.v20.i3.706. [PubMed: 24574744]. [PubMed Central: PMC3921480].

22. Sbrozzi-Vanni A, Zullo A, Di Giulio E, Hassan C, Corleto VD, Lah- ner E, et al. Low prevalence of idiopathic peptic ulcer disease: An Italian endoscopic survey. Dig Liver Dis. 2010;42(11):773-6. doi: 10.1016/j.dld.2010.03.019. [PubMed: 20444661].

23. Kanno T, Iijima K, Abe Y, Yagi M, Asonuma S, Ohyauchi M, et al. A multicenter prospective study on the prevalence of Helicobacter pylorinegative and nonsteroidal anti-inflammatory drugs-negative idiopathic peptic ulcers in Japan.J Gastroenterol Hepatol. 2015;30(5):842-8. doi: 10.1111/jgh.12876. [PubMed: 25532720].

24. Huh CW, Kim BW. [Diagnosis of Helicobacter pylori Infection]. Korean J Gastroenterol. 2018;72(5):229-36. Ko. doi: 10.4166/kjg.2018.72.5.229. [PubMed: 30642138].

25. Mohammadian T, Ganji L. The diagnostic tests for detection of Helicobacter pylori infection. Monoclon Antib Immunodiagn Immunother. 2019;38(1):1-7. doi: 10.1089/mab.2018.0032. [PubMed: 30648911].

26. Gulmez SE, Lassen AT, Aalykke C, Dall M, Andries A, Andersen BS, et al. Spironolactone use and the risk of upper gastrointestinal bleeding: A population-based case-control study. Br J Clin Pharmacol. 2008;66(2):294-9. doi: 10.1111/j.1365-2125.2008.03205.x. [PubMed: 18507655].

27. Dall M, Schaffalitzky de Muckadell OB, Lassen AT, Hallas J. There is an association between selective serotonin reuptake inhibitor use and uncomplicated peptic ulcers: A population-based case-control study. Aliment Pharmacol Ther. 2010;32(11-12):1383-91. doi: 10.1111/j.13652036.2010.04472.x. [PubMed: 21050241].

28. Shah H, Yang TJ, Wudexi I, Solanki S, Patel S, Rajan D, et al. Trends and outcomes of peptic ulcer disease in patients with cirrhosis. Postgrad Med. 2020;132(8):773-80. doi: 10.1080/00325481.2020.1795485. [PubMed: 32654578].

29. Huang KW, Kuan YC, Chi NF, Huang YH, Luo JC, Chien LN. Chronic obstructive pulmonary disease is associated with increased recurrent peptic ulcer bleeding risk. Eur J Intern Med. 2017;37:75-82. doi: 10.1016/j.ejim.2016.09.020. [PubMed: 27727075].

30. Langman MJ, Cooke AR. Gastric and duodenal ulcer and their associated diseases. Lancet. 1976;1(7961):680-3. doi: 10.1016/s01406736(76)92790-2. [PubMed: 73651].

31. Saadat S, Yousefifard M, Asady H, Moghadas Jafari A, Fayaz M, Hosseini $\mathrm{M}$. The most important causes of death in Iranian population; a retrospective Cohort study. Emerg(Tehran). 2015;3(1):16-21. [PubMed: 26512364]. [PubMed Central: PMC4614603]. 